\title{
A sociedade digital e a resolução de conflitos: análise da lei 13.994/2020 sob a ótica das transformações digitais e do acesso à justiça.
}

\author{
The digital society and conflict resolution: analysis of law 13,994/2020 from the perspective
} of digital transformations and access to justice.

José Eduardo Lourenço dos Santos*

\author{
Thales Aporta Catelli**
}

Bruno Tulim Silva ${ }^{* * *}$

\section{REFERÊNCIA}

CATELLI, Thales Aporta; SANTOS, José Eduardo Lourenço dos; SILVA, Bruno Tulim. A sociedade digital e a resolução de conflitos: análise da lei 13.994/2020 sob a ótica das transformações digitais e do acesso à justiça. Revista da Faculdade de Direito da UFRGS, Porto Alegre, n. 45, p. 186-212, abr. 2021. DOI: https://doi.org/10.22456/0104-6594.108755.

\section{RESUMO}

O presente artigo tem por objeto a análise reflexiva acerca da sociedade digital e os métodos de resolução consensual de conflitos, com enfoque à Lei Federal brasileira no 13.994/2020, como garantia ao acesso à justiça. Inicia-se o estudo com a análise das espécies de resolução consensual de conflitos, elucidando-se como referido instituto propicia a garantia ao acesso à justiça, partindo-se da concepção de "acesso à ordem jurídica justa" à constatação de sua efetividade. Após, são analisadas as transformações digitais percebidas durante o transcorrer do tempo, destacando-se as características das inovações tecnológicas e o Direito, com a observação dos métodos digitais para resolução de conflitos, acolhendo, como paradigma, as plataformas digitais voltadas à auto composição, suas características relacionadas à inovação, bem assim considerações sobre as startups jurídicas, a sistemática de plataformas e os ecossistemas de inovação como garantes ao acesso à justiça, apresentado, finalmente, a conclusão alcançada com o estudo.

\section{PALAVRAS-CHAVE}

Transformação digital. Inovação tecnológica. Direito. Acesso à justiça.

\begin{abstract}
This article presents a reflective analysis of digital society and the methods of consensual resolution of conflicts, focusing on the Brazilian Federal Law n. 13.994/2020, as a guarantee of access to justice. The study begins with the analysis of the types of consensual conflict resolution, elucidating how this institute provides the guarantee of access to justice, starting from the concept of "access to the fair legal order" to the verification of its effectiveness. Afterwards, the digital transformations perceived over time are analyzed, highlighting the characteristics of technological innovations and the Law, with the observation of digital methods for conflict resolution, accepting, as paradigm, the digital platforms that aim to the autocomposition of conflicts, its characteristics related to innovation, as well as considerations about legal startups, the systematic of platforms
\end{abstract}

\footnotetext{
* Pós-Doutorando em Direito pela Universidade Estadual do Norte do Paraná (UENP), Pós-Doutor pela Universidade de Coimbra (área de Democracia e Direitos Humanos - 2016), Doutorado em Direito pela Universidade Federal do Paraná (UFPR - 2013), Mestrado em Direito pela Fundação de Ensino Eurípides Soares da Rocha (2002) e Graduação em Direito pela Fundação de Ensino Eurípides Soares da Rocha (1988). Atualmente é professor do Centro Universitário Eurípides de Marília-SP, Graduação e Mestrado, e Delegado de Polícia aposentado no Estado de São Paulo.

** Mestrando em Direito no Programa de Pós Graduação Stricto Sensu do Centro Universitário Eurípides de Marília (UNIVEM). Advogado.

*** Mestrando em Direito no Programa de Pós-Graduação Stricto Sensu do Centro Universitário Eurípides de Marília - UNIVEM. Advogado.
} 
and innovation ecosystems as guarantors of the access to justice and, finally, presenting the conclusions reached by the study.

\section{KEYWORDS}

Digital transformation. Tecnologic innovation. Law. Access to justice.

\section{SUMÁRIO}

1. Introdução. 2. Considerações acerca dos métodos de resolução consensual de conflitos. 2.1 Os métodos de resolução consensual de conflitos. 2.2 A resolução consensual de conflitos e o acesso à justiça. 3. Os métodos compositivos e a sociedade digital. 3.1 A inovação tecnológica no Direito - a organização exponencial e o caráter disruptivo. 3.2 Paralelo das a um modelo de empreendedorismo: as startups jurídicas. 3.3 Os ecossistemas de inovação e o universo jurídico: é possível quando o assunto é a composição das partes?. 4. Aspectos gerais sobre a lei 13. 994/2020. 4.1. As inovações tecnológicas como instrumentos garantidores do acesso à "ordem jurídica justa” por meio da conciliação. 5. Conclusão. Referências. Dados da publicação.

\section{INTRODUÇÃO}

Tema bastante debatido tanto na academia quanto nas organizações estatais e por operadores do direito é o acesso à justiça. E não se faz discussão recente, considerando, como exemplo, as previsões relacionadas à temática na Declaração Universal dos Direitos Humanos, datada de 1948, e o estudo denominado Projeto Florença, coordenado por Mauro Cappelletti, desenvolvido por volta de 1970, do qual originou-se diversas obras. Estes, embora em período passado, mostram-se, pode-se dizer, até mesmo contemporâneos, quando comparados às raízes do acesso à justiça na antiguidade.

Indubitável, pois, que, embora talvez em menor intensidade, é possível constatar durante o transcorrer dos tempos que o acesso à justiça gradativamente ganhou forças e enfoque do Estado e das ciências jurídicas.

Tem-se, destarte, uma infinidade de estudos relacionados à identificação de máculas relacionadas ao acesso à justiça, e as formas de mitigação destas, dentre as quais destacam-se os métodos consensuais voltados à resolução extrajudicial de conflitos.

Para tanto, inúmeras foram as medidas implementadas pautadas nos referenciados estudos e propostas, tais como à indicação da conciliação e mediação pré-processual, fixação de normativas voltadas à regulamentação do tema pelos entes legislativos e o início de movimento objetivando uma verdadeira modificação estrutural no que concerne à neutralização da cultura do litígio.

Diante da intensificação, ainda no âmbito do Direito, do enfoque ao tema, considerando às características da chamada sociedade digital e ante o surgimento das inovações tecnológicas, constatou-se a incidência da chamada transformação digital nos procedimentos e métodos antes tratados apenas na seara da dogmática jurídica, o que significou uma modificação sem 
precedentes nas conceituações anteriormente dispostas e propiciou uma abrangência das discussões e propostas à solução dos problemas enfrentados para além das matérias jurídicas.

Houve, assim, o surgimento de inúmeros instrumentos digitais relacionados à busca pela efetivação do acesso à justiça, dentre estes as plataformas digitais para resolução de conflitos.

O Estado, entretanto, embora regulando a matéria no âmbito jurisdicional, manteve-se inerte acerca das possibilidades apresentadas externamente ao Poder Judiciário, até que, em função da pandemia do COVID-19 enfrentada entre os anos de 2019 e 2020, com a promulgação da Lei Federal no 13.994/2020, que implementou a chamada audiência por vídeo conferência no âmbito dos procedimentos intrínsecos à Lei Federal no 9.099/95 - Lei dos Juizados Especiais Cíveis, houve o que aparenta ser um passo à implementação, na seara da auto composição, de elementos intrínsecos à transformação digital no Judiciário.

Sobre estes aspectos se encontra o objeto específico da presente análise: o estudo sobre o histórico da resolução consensual de conflitos e as características relacionadas à interferência da sociedade digital e suas transformações, a fim de traçar parâmetros acerca dos referidos temas e a garantia ao acesso à justiça.

Adotou-se o método hipotético-dedutivo à elaboração do presente artigo, partindo-se, para tanto, da pesquisa bibliográfica legislativa, jurisprudencial, de produções acadêmicas e doutrinárias, intentando-se que, ao final destas considerações, haja a contribuição e fomento às discussões sobre o tema, sem pretensões quaisquer de esgotamento deste.

\section{CONSIDERAÇÕES ACERCA DOS MÉTODOS DE RESOLUÇÃO CONSENSUAL DE CONFLITOS}

O Estado contemporâneo, assim como aquele que se via em seus primórdios, com detentor do monopólio de controle social mediante a criação e guarda de suas normativas, detém, consequentemente, o direito como forma de regulamentação social.

En el terreno del tratamiento de los conflictos en la vida en sociedad, el derecho regula las acciones y es un instrumento privilegiado de los Estados modernos para interceder en la interacción entre los sujetos. Pone un orden regulador de las transacciones y del intercambio.

Si bien se trata de una regulación heterónoma, se vuelve autónoma cuando es internalizado a través de la conformación de la cultura y los procesos de socialización. 
La cultura nos moldea y vuelve partícipe (parte de), como actores que adecuamos nuestras conductas a la norma internalizada como "deber ser". 1

Nesse sentido, parece razoável entender, pois, o Estado como reflexo da sociedade, e esta como formadora daquele, ambos, destarte, interagindo de forma cíclica e contínua, e, quando concernente à formação normativa, os anseios de um, em regra, convergem à reação do outro.

Ocorre que diante de determinados problemas ou temas, em inúmeras hipóteses, o que se vê é a dicotomia de entendimentos e concepções subjetivas que, analisadas casuisticamente, enseja à sociedade o clamor ao Estado para que este providencie a pacificação da celeuma e este, em um primeiro momento, impera a lei como forma de resolução da matéria, sem, contudo, sanar a essência do problema.

É evidente que a formação sociocultural ou os problemas socioambientais não se mostram passíveis de manipulação ou pacificação por mero procedimento Estatal, e não é o que se exige. Porém, é fato que deve ser trazido ao estudo, porque nessa constante interação, invariavelmente, os operadores do direito encontram-se expostos às realidades jurídicoculturais e sociais o que, somado aos seus próprios anseios e concepções, normalmente, ocasiona a influência no modus operandi destes profissionais.

Diante dessa considerável carga de influências e a natureza do exercício das funções jurídicas, bem assim a própria aproximação e adoção de teses antagônicas pelos operadores do direito, originou a manutenção, por relevante tempo, da chamada "cultura do litígio", ou seja, a resolução dos problemas sociais levados à resolução por meio da justiça, com a instrumentalização dos diálogos por meio de processos burocráticos.

Ocorre que, da mesma forma, as celeumas sub judice, em especial nos procedimentos contenciosos, não recebem a pacificação do conflito pelo Estado, mas tão somente a dicção do direito, isto é, a ratificação casuística ao caso específico das normas ditadas por aquele em momento pretérito.

Tem-se, portanto, que, embora a judicialização (vide a cultura do litígio) possa eventualmente ser eficaz sob os aspectos numéricos referentes aos resultados de julgamentos

\footnotetext{
1"No campo de lidar com conflitos na vida da sociedade, o direito regula as ações e é um instrumento privilegiado dos Estados modernos para interceder na interação entre os sujeitos. Estabelece uma ordem regulatória para transações e trocas. Embora seja uma regulação heterônoma, ela se torna autônoma quando internalizada através da conformação dos processos de cultura e socialização. A cultura nos molda e nos torna um participante (parte de), como atores que adaptam nossos comportamentos à norma internalizada como "deve ser"." GRECO, Silvana. Los aportes de la mediación y de los procesos colaborativos de gestión de conflictos para la transformación de la cultura del litigio. Revista de Ciencias Jurídicas y Sociales, n. 4, 2006, p. 4.
} 
proferidos ou causas resolvidas, a essência dos problemas, quer dizer o âmago motivacional que ensejara o embate em regra mantém-se enclausurado.

Diante dessa realidade, o estudo das resoluções consensuais de conflitos mostra-se essencial, pois se figura como investigação das formas efetivas para solução das celeumas. Contudo, assim o faz de forma profunda, não somente com a entrega do direito, mas com a pacificação do litígio

\subsection{OS MÉTODOS DE RESOLUÇÃO CONSENSUAL DE CONFLITOS}

Como métodos para resolução consensual de conflitos pode-se destacar a negociação, a mediação, a conciliação e a arbitragem.

Originalmente estos procedimientos que comprenden métodos diversos como la negociación, la facilitación, la mediación, el arbitraje, el mini juicio, el ombusman, se los considero alternativos al litigio y se los llamó "métodos alternativos de solución de controversias" MASC, "resolución alternativa de Conflictos" RAD; en inglés "ADR". Hoy se perfilan como un campo de prácticas con especificidad y existe una tendencia a denominarlas "procesos colaborativos de gestión y tratamiento de las diferencias y conflictos"; "métodos participativos de justicia"; "métodos adecuados /apropiados de tratamiento de conflictos". ${ }^{2}$

Nesse contexto, destaca Vasconcelos que a negociação:

É lidar diretamente, sem a interferência de terceiros, com pessoas, problemas e processos, na transformação ou restauração de relações, da solução de disputas ou trocas de interesses. A negociação, em seu sentido técnico, deve estar baseada em princípios. Deve ser cooperativa, pois não tem por objetivo eliminar, excluir ou derrotar a outra parte. Nesse sentido, a negociação (cooperativa), dependendo da natureza da relação interpessoal, pode adotar o modelo integrativo (para relações continuadas) ou o distributivo (para relações episódicas). Em qualquer circunstância busca-se um acordo de ganhos mútuos. ${ }^{3}$

A mediação, por sua vez, se trata se um meio de solução de disputas, em regra não hierarquizado, em que duas ou mais pessoas, utilizando-se da colaboração de um terceiro, o mediador, expõem o problema, são escutadas e questionadas, dialogam construtivamente e

\footnotetext{
2 "Originalmente, esses procedimentos, que incluem diversos métodos, como negociação, facilitação, mediação, arbitragem, mini-julgamento, ombusman, eram considerados alternativos ao litígio e eram chamados de 'métodos alternativos de resolução de disputas' MASC, 'resolução alternativa de conflitos' RAD; em inglês 'ADR'. Hoje eles são delineados como um campo específico de prática e há uma tendência a chamá-los de 'processos colaborativos de gestão e tratamento de diferenças e conflitos'; 'Métodos participativos de justiça'; 'Métodos apropriados / apropriados de gerenciamento de conflitos"'. GRECO, Silvana. Los aportes de la mediación y de los procesos colaborativos de gestión de conflictos para la transformación de la cultura del litigio. Revista de Ciencias Jurídicas y Sociales, n. 4, 2006, p. 2.

${ }^{3}$ VASCONCELOS, Carlos Eduardo. Mediação e práticas restaurativas. São Paulo : Método, 2008, p. 35.
} 
procuram identificar os interesses comuns, opções e, eventualmente, firmar um acordo ${ }^{4}$.

Cumpre esclarecer que o mediador deve ser apto, imparcial, independente e livremente escolhido ou aceito, e atuará de modo a colaborar com os mediandos para que eles pratiquem uma comunicação construtiva e identifiquem seus interesses e necessidades comuns ${ }^{5}$.

De se destacar, nesse sentido, que a mediação possui, em regra, dois enfoques: i) um primeiro visa à reconstrução ou pacificação da relação entre as partes; ii) um segundo se volta à formalização de um acordo.

Quais os conflitos que melhor se prestam à mediação focada na relação?

Conflitos familiares, comunitários, escolares e corporativos, entre pessoas que habitam, convivem, estudam ou trabalham nas mesmas residências, ruas, praças, clubes, associações, igrejas, bares, escolas, empresas, etc. Mediação familiar, para os conflitos domésticos ou no âmbito da família; mediação comunitária, para conflitos de vizinhança, mediação escolar, no ambiente das instituições de educação, inclusive quando na praticada pelos próprios alunos em relação aos seus conflitos recíprocos; mediação corporativa, para os conflitos no ambiente empresarial ${ }^{6}$.

A mediação que prioriza o acordo pode ser denominada como conciliação, e

é apropriada para lidar com relações eventuais de consumo e outras relações casuais em que não prevalece o interesse comum de manter um relacionamento, mas apenas o objetivo de equacionar os interesses materiais ${ }^{7}$.

Por fim, no que concerne à arbitragem, tem-se a se destacar que se trata "de um instituto com duas naturezas jurídicas que se completam: a contratual e a jurisdicional"8.

A arbitragem é um instituto do Direito. É prevista em leis e convenções internacionais, com destaque para a Convenção de Nova York, de 1958. Aqui no Brasil, a norma básica sobre a arbitragem é a Lei 9.307/2006 ("Lei Marco Maciel"). As pessoas podem optar pela solução das suas disputas por intermédio da arbitragem. Nesse caso, o papel do terceiro, diferente do que ocorre na mediação, não será mais o de facilitar o entendimento - embora na dinâmica do processo arbitral isso sempre seja possível e recomendável -, mas o de colher as provas, argumentos e decidir mediante laudo ou sentença arbitral irrecorrível. ${ }^{9}$

Cumpre esclarecer que, no Brasil, a realidade é diferente.

Não há no Brasil - como há em outros países, a exemplo de Portugal, Argentina, Canadá e Estados Unidos - uma legislação que regulamente as práticas cobertas pela denominação mediação de conflitos, nem tampouco uma profissionalização de mediadores. Do mesmo modo, as definições do que sejam mediação judicial e mediação extrajudicial parecem estar mais delimitadas pelas instituições que aplicam seus princípios. Assim sendo, a mediação judicial está associada aos princípios

\footnotetext{
${ }^{4}$ VASCONCELOS, Carlos Eduardo. Mediação e práticas restaurativas. São Paulo : Método, 2008, p. 36.

${ }^{5}$ Ibid., p. 36.

${ }^{6}$ Ibid., p. 37.

${ }^{7}$ Ibid., p. 38.

${ }^{8}$ Ibid., p. 39.

${ }^{9}$ Ibid., p. 39.
} 
colocados em prática no interior das instituições judiciais, ou seja, quando partes em conflito são encaminhadas por um juiz para sessões de mediação, no contexto do processo judicial; e, por oposição, a mediação extrajudicial está ligada ao que ocorre fora dos muros dessas instituições e dos processos judiciais propriamente ditos. ${ }^{10}$

Insta consignar, ademais, que, embora há tempos já se fale acerca de métodos para resolução consensual de conflitos, o tema ganhou força com a Resolução $\mathrm{n}^{\circ} 125$, de 29 de novembro de 2010, do Conselho Nacional de Justiça - CNJ, a qual, tratando-se sobre o tema com a denominação tratamento adequado dos conflitos de interesses no âmbito do Poder Judiciário, regulamentou, no âmbito das atribuições daquele poder, a utilização da conciliação e mediação. ${ }^{11}$

A matéria ganhou ainda mais força, entretanto, quando, no ano de 2015, foi aprovado o então chamado Novo Código de Processo Civil Brasileiro - NCPC, com a promulgação da Lei Federal $\mathrm{n}^{\circ} 13.105$, de 16 de março daquele ano.

Isto porque o NCPC trouxe em suas disposições, inclusive como normas fundamentais do processo civil, a ratificação da arbitragem como forma de solução extrajudicial de conflitos, assim como o dever aos juízes, advogados, defensores públicos e membros do Ministério Público, de estimularem a conciliação, a mediação e outros métodos de solução consensual, inclusive no curso do processo judicial ${ }^{12}$.

Há uma interessante reflexão diante desse contexto: a resolução de conflitos sob a ótica do acesso à justiça. Isto porque, sob uma análise sociológica, partindo-se da apreciação subjetiva dos próprios mediadores extrajudiciais, no que concerne à utilização da conciliação e mediação no âmbito interno do judiciário, o tema estaria, em tese, mais relacionado à celeridade processual economia processual ${ }^{13}$, o que parece, considerando os aspectos relativos ao acesso à justiça, debate relevante.

\footnotetext{
${ }^{10}$ MELLO, Kátia Sento Sé; BAPTISTA, Bárbara Gomes Lupetti. Mediação e conciliação no judiciário: dilemas e significados. Dilemas-Revista de Estudos de Conflito e Controle Social, v. 4, n. 1, p. 97-122, 2011, p. 99.

${ }^{11}$ CONSELHO NACIONAL DE JUSTIÇA. Resolução $n^{o}$ 125, de 29 de novembro de 2010. Disponível em: https://atos.cnj.jus.br/atos/detalhar/atos-normativos?documento=156. Acesso em 12.06.2020.

12 "Art. $3^{\circ}$ Não se excluirá da apreciação jurisdicional ameaça ou lesão a direito. $\$ 1^{\circ}$ É permitida a arbitragem, na forma da lei. §2 $2^{\circ} \mathrm{O}$ Estado promoverá, sempre que possível, a solução consensual dos conflitos. $\S 3^{\circ} \mathrm{A}$ conciliação, a mediação e outros métodos de solução consensual de conflitos deverão ser estimulados por juízes, advogados, defensores públicos e membros do Ministério Público, inclusive no curso do processo judicial". BRASIL. Lei Federal $\mathrm{n}^{\circ}$ 13.105, de 16 de março de 2015 - Código de Processo Civil Brasileiro. Disponível em: http://www.planalto.gov.br/ccivil_03/_ato2015-2018/2015/lei/113105.htm. Acesso em: 12.06.2020.

${ }^{13}$ OLIVEIRA, Marcella Beraldo de. Justiças do diálogo: uma análise da mediação extrajudicial. 330f. Tese (Doutorado em Ciências Sociais) - Universidade Estadual de Campinas, Instituto de Filosofia e Ciências Humanas, Campinas/SP, 2010.
} 


\title{
2.2 A RESOLUÇÃO CONSENSUAL DE CONFLITOS E O ACESSO À JUSTIÇA
}

De suas origens arcaicas percebidas desde o surgimentos das Cidades-Estados Romanas, passando pelas primeiras manifestações do Estado inglês ao auxílio aos pobres com o Forma Pauperis, datado de 1495, e surgimento do dever beneficente dos advogados para defesa das causas dos desamparados no direito francês com o Code de l'Assistance Judiciaire, do ano de $1851^{14}$, replicado na Inglaterra (em 1883) e Estados Unidos (em 1892), bem assim a adoção, pelo Estado, nas práticas voltadas à garantia da justiça aos necessitados com previsão do Legal Aid and Advice Bill ${ }^{15}$, as questões concernentes à garantia de acesso à justiça sempre estiveram sob os olhares dos operadores e teóricos do direito.

Dentre eles destaca-se Mauro Cappellette que, entre os anos de 1965 e 1970, com o chamado "Projeto Florença" desenvolveu estudo comparado acerca do acesso à justiça, apresentando as chamadas ondas renovatórias.

\begin{abstract}
O recente despertar de interesse em torno no acesso efetivo à Justiça levou a três posições básicas, pelo menos nos países do mundo Ocidental. Tendo início em 1965, estes posicionamentos emergiram mais ou menos em sequência cronológica. Podemos afirmar que a primeira solução para o acesso - a primeira onda desse movimento novo - foi a assistência judiciária; a segunda dizia respeito às reformas tendentes a proporcionar a representação jurídica para os interesses "difusos", especialmente nas áreas da proteção ambiental e do consumidor; e o terceiro - e mais recente - é o que nos propomos a chamar simplesmente "enfoque de acesso à justiça" porque inclui os posicionamentos anteriores, mas vai muito além deles, representando, dessa forma, uma tentativa de atacar as barreiras ao acesso de modo mais articulado e compreensivo. ${ }^{16}$
\end{abstract}

Durante o projeto, foram identificados obstáculos que maculavam o acesso à justiça ${ }^{17}$ :

O primeiro deles era de natureza financeira, isto porque para garantia de prestação da tutela jurisdicional, o tutelado deveria arcar com altos custos judiciais que impossibilitava grande parte da população carente da época.

Haviam também os obstáculos de natureza temporal, quer dizer, o processo judicial viase extremamente demorado.

\footnotetext{
${ }^{14}$ ALVES, Cleber Francisco. A estruturação dos serviços de assistência jurídica nos Estados Unidos, na França e no Brasil e sua contribuição para garantir a igualdade de todos no Acesso à Justiça. Orientador: José Ribas Vieira - Rio de Janeiro: PUC-Rio, Departamento de Direito, 2005, p. 50.

${ }^{15}$ ALVES, Cleber Francisco. A estruturação dos serviços de assistência jurídica nos Estados Unidos, na França e no Brasil e sua contribuição para garantir a igualdade de todos no Acesso à Justiça. Orientador: José Ribas Vieira - Rio de Janeiro: PUC-Rio, Departamento de Direito, 2005, p. 50.

${ }^{16}$ CAPPELLETTI, Mauro; GARTH, Bryant. Acesso à justiça. Trad. e Rev. Ellen Gracie Northfleet. Porto Alegre, 1982, p. 12.

${ }^{17}$ MARINONI, Luis Guilherme. Novas linhas do processo civil: o acesso à justiça e os institutos fundamentais do direito processual. 2. ed. São Paulo: Revista dos Tribunais, 1997, p. 25-40.
} 
Um terceiro fator era de natureza psicológica e cultural, o que significa dizer que grande parcela vulnerável da população sequer detinha conhecimento dos direitos a ela inerente e, quando o tinha, não confiava no judiciário para garanti-los.

Somado aos três últimos obstáculos anteriormente narrados, haviam as problemáticas institucionais, o que demonstrava falha sistêmica no que concernia à garantia de direitos coletivos ou difusos, por exemplo, em que a insignificância da lesão experimentada individualmente obstava a busca pelo direito que, no âmbito transindividual via-se gravemente maculado.

Imprescindível destacar que os problemas apontados no "Projeto Florença" mostramse, também, contemporâneos e, nesse contexto, destaca-se que, tomando como premissa os óbices apontados, para garantir o acesso à justiça em sentido material, é necessário o enfrentamento de todos aqueles obstáculos ${ }^{18}$.

Uma solução é a implementação de meios alternativos de resolução de controvérsias que visem impactar favoravelmente tanto a eficiência no tempo da prestação jurisdicional quanto na qualidade da resolução do conflito, a exemplo, justamente, dos meios alternativos mais utilizados, em especial a conciliação, a mediação e a arbitragem.

Quando tratando do tema acesso à justiça, imprescindível atentar à expressão cunhada por Kazuo Watanabe, a saber: acesso à ordem jurídica justa ${ }^{19}$.

Referido termo denota-se de tamanha importância justamente porque, diante do contexto de superação das máculas apontadas por Mauro Cappellette por meio da resolução extrajudicial de conflitos com a utilização conciliação, mediação e arbitragem, o acesso à justiça amplo se mostra mais próximo de ser atendido, justamente por abranger a atenção ao acesso à ordem jurídica justa não somente pela mera prestação da tutela jurisdicional pelo Estado, mas pela garantia de que haverá a pacificação do conflito social de forma efetiva.

Ocorre que, externando perspectiva subjetiva, concebe-se que a operacionalização da justiça deve, impreterivelmente, acompanhar a evolução social, não somente no que concerne as normativas formais ou materiais, mas a própria implementação de sistemáticas voltadas à otimização da prestação jurisdicional.

Nesse sentido, tem-se que os métodos compositivos na sociedade digital devem somarse aos benefícios e facilitações trazidos pelas inovações tecnológicas, pois indubitável o

\footnotetext{
${ }^{18}$ SOUZA, Luciana Moessa de (org.). Mediação de conflitos: novo paradigma de acesso à justiça. 2 ed. Santa Cruz do Sul: Essere nel Mondo, 2015, p. 50.

${ }^{19}$ WATANABE, Kasuo. Acesso à ordem jurídica justa / Conceito atualizado de acesso à justiça / Processos coletivos e outros estudos. Del Rey: Belo Horizonte, 1969, p. 10.
} 
potencial à garantia ao acesso à justiça quando nesta união, como passa-se a narrar adiante.

\section{OS MÉTODOS COMPOSITIVOS E A SOCIEDADE DIGITAL}

Quando na análise etimológica da palavra tecnologia, identifica-se como conceito “teoria ou análise organizada das técnicas, procedimentos, métodos, regras, âmbitos ou campos da ação humana." 20

Nesse sentido, muito embora atualmente seja, o referido verbete, relacionado às concepções digitais, não se pode olvidar que a tecnologia, ao longo do tempo, modificou-se conforme a sociedade, que a detinha como instrumento para seu desenvolvimento, e evoluiu concomitantemente às necessidades e a atualização dos conceitos técnico-científicos elaborados e percebidos na época.

Tal reflexão fica evidente quando na análise das próprias revoluções industriais ocorridas durante o transcorrer temporal, as quais viram-se em constantes aprimoramentos voltados, invariavelmente, à facilitação e otimização dos processos enfrentados pelo ser humano em seu cotidiano.

Foi assim durante a Primeira Revolução Industrial, por volta do século XVIII, com a invenção do motor a vapor em 1769 e a Segunda Revolução Industrial, com o surgimento da eletricidade e a potencialização da comunicação à distância na segunda metade do século XIX ${ }^{21}$.

O domínio sobre tais tecnologias figurou, desde os primórdios, o controle e o poder em sociedade.

A Terceira Revolução Industrial, caracterizada pelos avanços tecnológicos na microeletrônica e telecomunicações ${ }^{22}$, por sua vez, abriu caminho para o nascimento da sociedade da informação, devido a sua dependência da tecnologia e da ciência ${ }^{23}$.

\footnotetext{
${ }^{20}$ TECNOLOGIA. In: Dicionário online de português. Disponível em: https://www.dicio.com.br/tecnologia/. Acesso em 29.06.2020.

${ }^{21}$ CARVALHO, Angela Maria Grossi de; SANTOS, Plácida Leopoldina Ventura Amorim da Costa. Sociedade da informação e a aplicação da informação na sociedade contemporânea. In: DT5 do IX Encontro dos Grupos/Núcleos de Pesquisas em Comunicação, XXXII Congresso Brasileiro de Ciências da Comunicação. Curitiba, 2009, p. 02. Disponível em: http://www.intercom.org.br/papers/nacionais/2009/resumos/R4-2483-1.pdf 22 VIEIRA, Tatiana Cuberos; CASTANHO; Maria Eugênia. Sociedade atual e revolução da informação: ganhos e perdas. Contrapontos - volume 8 - n.2 - p. 171-185 - Itajaí, mai/ago 2008, p. 173.

${ }^{23}$ CARVALHO, Angela Maria Grossi de; SANTOS, Plácida Leopoldina Ventura Amorim da Costa. Sociedade da informação e a aplicação da informação na sociedade contemporânea. In: DT5 do IX Encontro dos Grupos/Núcleos de Pesquisas em Comunicação, XXXII Congresso Brasileiro de Ciências da Comunicação. Curitiba, 2009, p. 02, Disponível em: http://www.intercom.org.br/papers/nacionais/2009/resumos/R4-2483-1.pdf
} 
A Quarta Revolução Industrial, sem parâmetros precedentes, modifica por completo os conceitos anteriores, é a fase em que negócios e tecnologias relacionam-se essencialmente.

Nesse sentido, faz-se interessante destacar que, invariavelmente, quando se fala em domínio da tecnologia como a detenção do poder social, faz-se imprescindível destacar a relação do poder também em seus sentidos econômico-financeiros. Logo, a detenção da informação, em uma sociedade com as características contemporâneas, considerando ver-se recente tal caráter, é dizer que a sociedade atual se amolda, em seus mais diversos aspectos e setores, as inovações e transformações, hoje digitais.

Daí, portanto, a possibilidade de conceituação da sociedade digital, marcada por diversos fatores, como a modificação na forma de negócios e relações sociais e o surgimento de organizações digitais.

Interessante destacar que, no que concerne à seara jurídica esta, em regra, sempre se atentou às análises concernentes às respostas ou amoldamentos necessários do direito às inovações e, consequentemente, às novas tecnologias.

Ocorre que, diferentemente dos pressupostos tradicionalistas, importante destacar as contribuições das ciências tecnológicas e inovadoras ao direito contemporâneo, a exemplo das facilitações propiciadas nos mais diversos âmbitos da implementação da justiça.

A inovação trazida pela digitalização do processo e a implementação das tecnologias relacionadas à inteligência artificial como, por exemplo, o chamado Projeto Victor ${ }^{24}$ implementado no Supremo Tribunal Federal brasileiro ${ }^{25}$, são exemplos da incidência da tecnologia e inovação do âmbito do Poder Judiciário brasileiro.

A de se destacar, porém, que estes são exemplos de otimizações voltadas à resolução de celeumas já judicializadas, o que, destaca-se, se mostra crucial atualmente.

\footnotetext{
${ }^{24}$ PEIXOTO, Fabiano Hartmann. Projeto Victor: relato do desenvolvimento da inteligência artificial na repercussão geral do Supremo Tribunal Federal. Revista Brasileira de Inteligência Artificial e Direito. v.1, 2020. Disponível em: https://rbiad.com.br/index.php/rbiad/article/view/4.

${ }^{25}$ Sobre o Projeto Victor: "Na fase inicial do projeto, VICTOR irá ler todos os recursos extraordinários que sobem para o STF e identificar quais estão vinculados a determinados temas de repercussão geral. Essa ação representa apenas uma parte (pequena, mas importante) da fase inicial do processamento dos recursos no Tribunal, mas envolve um alto nível de complexidade em aprendizado de máquina. VICTOR está na fase de construção de suas redes neurais para aprender a partir de milhares de decisões já proferidas no STF a respeito da aplicação de diversos temas de repercussão geral. O objetivo, nesse momento, é que ele seja capaz de alcançar níveis altos de acurácia - que é a medida de efetividade da máquina -, para que possa auxiliar os servidores em suas análises. A expectativa é de que os primeiros resultados sejam mostrados em agosto de 2018" (SUPREMO TRIBUNAL FEDERAL. Inteligência artificial vai agilizar a tramitação de processos no STF. Notícias STF. Publicado em quarta-feira, 30 de maio de 2018. Disponível em: http://www.stf.jus.br/portal/cms/verNoticiaDetalhe.asp?idConteudo=380038. Acesso em 12.06.2020).
} 
Contudo, de se atentar à contemporânea, porém atemporal, tendência às respostas jurídicas extrajudiciais, como a já mencionada resolução consensual de conflitos, haja vista as próprias preconizações da Carta Magna no que concerne à economicidade administrativa, economia, celeridade e efetividade processual e demais embasamentos principiológicos que, embora intentem imperar à entrega da tutela jurisdicional plena em seus mais diversos aspectos, atualmente parecem servir tão somente como parâmetros para a constatação de que a atual situação da justiça brasileira se percebe extremamente custosa, morosa e, por vezes, pouco, ou até mesmo não, efetiva ${ }^{26}$.

Nesse contexto, de se destacar que, externamente ao âmbito do judiciário, diversas organizações buscaram, seja na forma altruísta ou business, a implementação de sistemáticas tecnológicas e inovadoras à disponibilização de formas de resolução de conflitos apartada da tutela estatal ou, por vezes, utilizando-se do Estado apenas à homologação dos acordos.

Muitas destas organizações utilizaram, para tanto, a implementação de plataformas online digitais para otimização da resolução consensual e, sobre estes aspectos, faz-se interessante, destarte, a análise sob a ótica da transformação digital, do surgimento e características das referidas tecnológicas e inovações neste âmbito.

\subsection{A INOVAÇÃO TECNOLÓGICA NO DIREITO - A ORGANIZAÇÃO EXPONENCIALE O CARÁTER DISRUPTIVO}

Há determinada perspectiva preceitual a inovação como "instrumento específico dos empreendedores, o processo pelo qual eles exploram a mudança como uma oportunidade para um negócio diferente ou um serviço diferente" ${ }^{27}$.

Aparenta-se adequada, entretanto, as concepções trazidas por Chris Freeman, isto

\footnotetext{
26 "No ano de 2018, as despesas totais do Poder Judiciário somaram R \$ 93,7 bilhões, o que representou redução de $0,4 \%$ em relação ao último ano." "Descontadas tais despesas, o gasto efetivo para o funcionamento do Poder Judiciário é de $\mathrm{R} \$ 76,8$ bilhões, a despesa por habitante é de $\mathrm{R} \$ 368,4$, e consome-se 1,1\% do PIB.A despesa da Justiça Estadual, segmento que abrange 80\% dos processos em tramitação, corresponde a aproximadamente $57 \%$ da despesa total do Poder Judiciário (Figura 22). Na Justiça Federal, a relação é de 13\% dos processos para 12\% das despesas, e na Justiça Trabalhista, 6\% dos processos e 20\% das despesas." Apesar da expressiva despesa do Poder Judiciário, os cofres públicos receberam durante o ano de 2018, em decorrência da atividade jurisdicional, cerca de $\mathrm{R} \$ 58,6$ bilhões, um retorno da ordem de $63 \%$ das despesas efetuadas. Esse foi o maior montante auferido na série histórica. Somente em 2009 e 2018, a arrecadação superou o patamar de 60\%". "Os gastos com assistência judiciária gratuita equivalem a 1,09\% do total das despesas do Poder Judiciário, ao custo de R \$4,91 por habitante." CONSELHO NACIONAL DE JUSTIÇA. Justiça em Números 2019/Conselho Nacional de Justiça. Disponível em: https://www.cnj.jus.br/pesquisas-judiciarias/justica-em-numeros/. Acesso em: 29.06.2020.

${ }^{27}$ DRUCKER, Peter Ferdinand. Inovação e espirito empreendedor: práticas e princípios. São Paulo: Pioneira, 1986.
} 
porque extrai da seara meramente comercial a conceituação da terminologia, veja:

[...] um dos problemas em gerir a inovação é a variedade de entendimentos que as pessoas têm desse termo, frequentemente confundindo-o com invenção. [...] Inovação é o processo de tornar oportunidades em novas idéias e colocar estas em prática de uso extensivo. ${ }^{28}$ [sic] [grifos nossos]

Nesse sentido, Guilherme Ary Plonsky afirma que são três os equívocos conceituais frequentes no entendimento da inovação tecnológica: reducionismo (considerar inovação apenas a de base tecnológica), encantamento (considerar inovação tecnológica apenas a espetacular) e descaracterização (relaxar o requisito de mudança tecnológica dessa inovação) ${ }^{29}$.

Segundo o Marco Legal de Ciência, Tecnologia e Inovação (Lei n ${ }^{\circ}$ 13.243), inovação tecnológica seria:

Introdução de novidade ou aperfeiçoamento no ambiente produtivo e social que resulte em novos produtos, serviços ou processos ou que compreenda a agregação de novas funcionalidades ou características a produto, serviço ou processo já existente que possa resultar em melhorias e em efetivo ganho de qualidade ou desempenho ${ }^{30}$.

A inovação tecnológica é caracterizada pela presença de mudanças tecnológicas em produtos (bens ou serviços) oferecidos à sociedade, ou na forma pela qual produtos são criados e oferecidos (que é usualmente denominada de inovação no processo). ${ }^{31}$

Conclui-se dos conceitos anteriormente elencados, portanto, que a inovação poderia ser entendida como a transformação de ideias anteriormente estabelecidas acerca de serviços, produtos ou procedimentos a fim de aprimorá-los e, no que concerne às plataformas de resolução de conflitos online, esta são, invariavelmente, exemplos de inovação.

Isto porque, veja que os métodos consensuais eram instrumentos jurídicos existentes. Com as plataformas online houve incremento no procedimento, portanto inovação.

Sobre outra perspectiva, de se atentar que, com a evolução e surgimento de plataformas diversas, considerando as especificidades e características destas, há constante modificação na forma de fornecimento do serviço, o que enseja a compreensão de a inovação também está presente no que concerne aos modelos e produtos oferecidos.

Há de se destacar que a inovação também pode ser apreciada sobre o prisma de sua

\footnotetext{
${ }^{28}$ FREEMAN, Chris. The economics of industrial innovation. 2. ed. London: Frances Pinter, 1982.

${ }^{29}$ PLONSKI, Guilherme Ary. Bases para um movimento pela inovação tecnológica no brasil. SÃO PAULO EM PERSPECTIVA, v. 19, n. 1, p. 25-33, jan./mar. 2005, p. 27.

${ }^{30}$ BRASIL. Lei Federal no 13.243, de 11 de janeiro de 2016 - "Marco Legal de Ciência, Tecnologia e Inovação”. Disponível em: http://www.planalto.gov.br/ccivil_03/_ato2015-2018/2016/lei/113243.htm. Acesso em: 12.06.2020.

${ }^{31}$ PLONSKI, Guilherme Ary. Bases para um movimento pela inovação tecnológica no brasil. SÃO PAULO EM PERSPECTIVA, v. 19, n. 1, p. 25-33, jan./mar. 2005, p. 27.
} 
potencialidade, ou seja: disruptiva ou incrementadora.

Isto quer dizer que, a ideia pode servir à ruptura de modelos e paradigmas dos serviços ou produtos anteriormente estabelecidos (quando disruptiva), ou acrescer melhorias e evoluções naqueles (quando incrementais).

Modelo disruptivo nasce a partir de uma ideia simples que propõe uma mudança de mindset. Uma alteração na percepção e no hábito de determinado comportamento da vida. Na maioria das vezes, trata-se de insights, de captações até óbvias, que surgem a partir de lacunas da realidade posta. Propostas de condutas que, por serem percebidas como tão evidentes para os indivíduos, acabam por gerar escalabilidade, o que do ponto de vista do ecossistema de startups costuma ocorrer de forma célere e sem a necessidade de altos investimentos na sua gênese, - especialmente se comparados com os custos envolvidos em dinâmicas tradicionais. ${ }^{32}$

No que concerne às resoluções de conflitos por plataformas online, pode-se dizer que o modelo originariamente viu-se disruptivo.

Observe, como exemplo, que, desde de o ano de 2010, com a Resolução $\mathrm{n}^{\circ} 125^{33}$ do Conselho Nacional de Justiça - CNJ, já mencionada, bem assim com o Novo Código de Processo Civil de $2015^{34}$, também citado, há constante intensificação no direito brasileiro no que concerne à busca por formas de auto composição, destacando-se como instrumentos voltados à esta seara a implementação dos Centros Judiciários de Solução de Conflitos e Cidadania-CEJUSCs como entes singulares para solução de conflitos anteriormente ao litigio judicial.

Quando no surgimento das plataformas online com funções análogas àquelas, houve, indubitavelmente, a disruptura do modelo preexistente, com a quebra de conceitos e formas anteriormente fixados.

Sobre outra perspectiva, as plataformas implementadas posteriormente, utilizando-se das mesmas tecnologias, formas e modelo, que modificam aspectos propiciem inovações no que concerne à apresentação ou execução do produto, procedimento ou serviço, mas não suficientes à quebra de paradigmas preteritamente fixados (o que se percebe atualmente), esta figurará uma inovação incrementadora.

Nesse sentido, pode-se entender que, na origem das inovações tecnológicas relacionadas às plataformas digitais para resolução de conflitos, constatou-se o surgimento de uma inovação

\footnotetext{
${ }^{32}$ FEIGELSON, Bruno. Sandbox: primeiras reflexões a respeito do instituto. Revista de Direito e as Novas Tecnologias. vol. 1. ano 1. p. 31-48. São Paulo: Ed. RT, out.-dez. 2018, p. 33.

${ }^{33}$ CONSELHO NACIONAL DE JUSTIÇA. Resolução $n^{o} 125$, de 29 de novembro de 2010. Disponível em: https://atos.cnj.jus.br/atos/detalhar/atos-normativos?documento=156. Acesso em 12.06.2020.

${ }^{34}$ BRASIL. Lei Federal $n^{o}$ 13.105, de 16 de março de 2015 - Código de Processo Civil Brasileiro. Disponível em: http://www.planalto.gov.br/ccivil_03/_ato2015-2018/2015/lei/113105.htm. Acesso em: 12.06.2020.
} 
disruptiva no modelo, procedimento e serviço, enquanto, considerando o atual cenário, as atualizações conceituais posteriores àquela, por serem inovações incrementadoras, apresentam a otimização e aprimoramento dos modelos, procedimentos e serviços já estabelecidos.

Insta consignar, ademais, que muitas das organizações surgidas nesse ínterim, com os propósitos de compor o sistema de auto composição extrajudicial por meio de plataformas online foram, ou ainda são, modelos de startups, o que merece atenção deste estudo.

\subsection{PARALELO DAS A UM MODELO DE EMPREENDEDORISMO: AS STARTUPS JURÍDICAS}

Primeiramente, ressalta-se que startup é, em regra, associada à definição fixada por Eric Ries $^{35}$, qual seja: um grupo de pessoas à procura de um modelo de negócio, baseado em tecnologia, repetível e escalável, trabalhando em condições de extrema incerteza.

Há de se destacar, também, que, para o autor, algumas atividades são características nas startups, a saber: i) transformar ideias em produtos; ii) estudar o mercado e verificar a aceitação desse produto, e; iii) analisar se o produto é sustentável ou não, e continuar ou não no lançamento da nova ideia ${ }^{36}$.

Todos estes fatores, presentes, pois, em uma startup, mostram-se essencialmente relacionado a uma matriz: a identificação do valor, entendido como a solução para as dores do consumidor.

Para tanto, segundo Blank, torna-se essencial ouvir os potenciais clientes, investigar as suas necessidades e as características do mercado indo a campo, o que pode ser traduzido pelo seu lema "saia do prédio!", que se relaciona ao entendimento puro das necessidades do mercado $^{37}$.

Diante de todos estes conceitos e características relacionadas ao universo business parecem chocarem-se com as preceituações dogmáticas, sociológicas e filosóficas do direito, o que enseja o questionamento: seria possível uma startup jurídica e, principalmente, voltada à resolução de consensual de conflitos?

\footnotetext{
${ }^{35}$ RIES, Eric. A startup enxuta: como os empreendedores atuais utilizam a inovação contínua para criar empresas extremamente bem-sucedidas. São Paulo: Lua de Papel, 2012.

${ }^{36}$ SANTOS, Gabriel Sant'Ana Palma. Organizações exponenciais: uma análise do desenvolvimento de startups na incubadora MIDI Tecnológico. 236f. Tese (Doutorado em Engenharia). Universidade Federal de Santa Catarina, Centro Tecnológico, Programa de Pós-Graduação em Engenharia e Gestão do Conhecimento, Florianópolis, 2018.

${ }^{37}$ BLANK, Steve; DORF, Bob. Startup: manual do empreendedor. Alta Books Editora, 2014.
} 
A resposta é sim! E mais: há de se destacar que, diante das inovações digitais e as características intrínsecas à evoluções conceituais e tecnológicas, houve um significativo aumento das startups voltadas à seara jurídica. São as chamadas legaltechs e as lawtechs; empresas focadas no desenvolvimento e uso de tecnologias aplicadas ao direito ${ }^{38}$.

No Brasil, não se faz distinção entre os termos, enquanto no exterior se costuma referir a legaltech como startups que atendem a todo o mercado e lawtechs as que desenvolvem soluções tendo como público final os advogados. ${ }^{39}$

Não obstante às definições colacionadas, tem-se que as startups jurídicas possuem como objetos à busca pela implementação de procedimentos e medidas que visam mitigar, por meio da tecnologia, as dores do universo jurídico.

Veja que, sob estes aspectos, as preconizações de Eric Ries sobre as startups se alinham com as atividades desenvolvidas pelas referidas organizações atuantes no ramo das soluções jurídicas.

Nesse sentido, observe que, quando tratando-se da composição das partes em um litigio, vê-se, contemporaneamente, o constante ensejo à criação de plataformas voltadas ao referido tema, o que se mostra ensejado por inúmeros fatores, dentre eles às próprias máculas (dores) do judiciário como a morosidade, incerteza no julgamento, frustração na execução, custos com acesso à justiça, etc., que exaltam os valores a serem objetivados pelas startups.

Diante desse cenário, mostra-se compreensível que as startups voltadas à identificação da relação dores versus valores relacionadas à judicialização de conflitos e à opção de auto composição percebem-se em constante busca pelo aprimoramento das inovações tecnológicas, em busca de disrupção ou incremento dos modelos adotados, haja vista a constante e infindável necessidade desta seara e, por diversas vezes, assim o fazem por meio de plataformas digitais.

Tais plataformas mostram-se de grande efetividade justamente porque possibilitam, a um custo baixo, de forma célere e com menor complexidade, a conexão entre as partes, ensejando a mediação ou conciliação de forma efetiva.

Nesse sentido, tem-se que as startups são exemplos de meios de grande importância à garantia da aplicação das inovações tecnológicas no universo jurídico e, em especial, à garantia de acesso à ordem jurídica justa, como facilitadora dos processos de resolução consensual de

\footnotetext{
${ }^{38}$ SIMÕES, Janaína. Automação no direito: Um novo tipo de startup, as legaltechs, desenvolve sistemas tecnológicos para a área jurídica. Revista FAPESP, Ed. 271, set. 2018. ed. 271, set. 2018. Disponível em: https://revistapesquisa.fapesp.br/2018/09/18/automacao-no-direito/. Acesso em: 27.05.2020, p. 01.

39 SIMÕES, Janaína. Automação no direito: Um novo tipo de startup, as legaltechs, desenvolve sistemas tecnológicos para a área jurídica. Revista Pesquisa FAPESP, 2018. Disponível em: https://revistapesquisa.fapesp.br/2018/09/18/automacao-no-direito/. Acesso em: 27.05.2020.
} 
conflitos. Mas surge a questão: como fomentar este meio? Uma solução é a valorização e observância aos chamados ecossistemas de inovação.

\subsection{OS ECOSSISTEMAS DE INOVAÇÃO E O UNIVERSO JURÍDICO: É POSSÍVEL QUANDO O ASSUNTO É A COMPOSIÇÃO DAS PARTES?}

Segundo Audy e Piqué,

No Brasil, abordagens mais recentes estão adotando o conceito de Ecossistemas de Inovação, como equivalentes (sinônimos) a Áreas de Inovação. Esse conceito visa estabelecer um paralelo com a biologia e os ecossistemas naturais, onde a vida se cria, se adapta e evolui, com intensa interação e sinergia. ${ }^{40}$

"Deste modo, a noção de ecossistema de inovação parte do reconhecimento de que o modelo fechado de inovação já não mais satisfaz o atual paradigma de mercado [...]" ${ }^{41}$, isso porque "por meio de um ecossistema de inovação articulado, as empresas conseguem criar valor e evoluir" de forma conjunta ao entorno de uma inovação "produzindo de forma cooperativa, com objetivo de elaborar novos produtos que satisfaçam ao consumidor no mercado" ${ }^{42}$, ou, no presente caso, das soluções necessárias à justiça.

Um ecossistema de inovação, portanto,

"[...] modela a economia, ao invés da dinâmica de energia dos relacionamentos complexos que se formam entre atores e entidades, e sua funcionalidade é viabilizar desenvolvimento e inovação tecnológicos. Neste contexto, os atores seriam os recursos materiais (fundos, equipamentos, instalações etc.) e o capital humano (estudantes, professores, apoio, pesquisadores da indústria, representantes da indústria etc.) que moldam as instituições participantes do ecossistema. ${ }^{43}$

Tem-se, destarte, que, no âmbito das startups jurídicas, sua inserção em um ecossistema de inovação significa alavancar as potencialidades de seus objetivos, isso porque, como mencionado, a própria essência do sistema busca impulsionar as inovações tecnológicas percebidas.

No contexto apresentado nesse estudo, portanto, uma legaltech, quando voltada à implementação de modelos que visam propiciar formas de resolução consensual de conflitos,

\footnotetext{
40 AUDY, Jorge; PIQUÉ, Josep. Dos parques científicos e tecnológicos aos ecossistemas de inovação: Desenvolvimento social e econômico na sociedade do conhecimento. - Brasília, DF : ANPROTEC, 2016, p. 22.

${ }^{41}$ JOAQUIM, Bruna; MENDES, Fernando Lúcio; ESTEVES, Paulo Cesar Leite. Ecossistemas de inovação: uma análise exploratória da literatura. In: Anais do VIII Congresso Internacional de Conocimiento e Innovación (ciki). v. 1, n. 1, 2018, p. 03.

${ }^{42} \mathrm{KON}$, Anita. Ecossistemas de inovação: a natureza da inovação em serviços. Revista de Administração, Contabilidade, e Economia da Fundace, 2016.

${ }^{43}$ FOLZ, Christian. Ecossistema Inovação. Fábio Carvalho editores técnicos. Brasília, DF : Embrapa, 2014.
} 
quando inserida em um ecossistema de inovação, percebe-se como resultado uma amplificação das potencialidades desta organização o que, no âmbito jurídico, significa intensificar de forma positiva a abrangência e efetividade do acesso à ordem jurídica justa.

Não obstante a importância das inovações tecnológicas no âmbito da garantia à efetividade da justiça, no Brasil as circunstâncias fáticas e normativas mostram-se diferentes, sendo, a Lei Federal n 13.994/2020, novidade que, sob os aspectos trazidos à discussão, mostra-se bem-vinda.

\section{ASPECTOS GERAIS SOBRE A LEI 13. 994/2020}

Inegável que estamos vivenciando e coexistindo em uma sociedade digital. Tal afirmação é de fácil constatação, pois as mudanças tecnológicas vêm sendo propostas de forma mais contundente desde a $3^{\mathrm{a}}$ Revolução Industrial com o traço marcante da automação das indústrias e outros seguimentos, iniciando a "Era da Revolução das Tecnologias da Informação e Comunicação" e ainda impulsionado pela $4^{\text {a }}$ Revolução Industrial, responsável por relacionar as tecnologias e modificar a forma das pessoas conviverem, além de contribuir para que novas relações jurídicas surjam no contexto social por meio especialmente da inteligência artificial e big data.

Este cenário digital foi potencializado pelo momento pandêmico decorrente COVID-19 que, visivelmente, acelerou processos e inovações tecnológicas derivado de protocolos de saúde elaborados pela Organização Mundial de Saúde (OMS) que orientam o auto isolamento das pessoas, quando possível, ou o distanciamento social como medida de controle de contaminação viral. Tal situação extrema, por sua vez, pressiona as instituições públicas e privadas para soluções às demandas humanas que, por hora, estão impedidas de relacionar-se presencialmente.

No campo jurídico, inserido neste contexto tecnológico em contraste com os efeitos decorrentes da pandemia e isolamento social, surge, como resposta a uma das dores do regular trâmite processual, a possibilidade de conciliação não presencial conduzida por órgão jurisdicional.

Remonta de um passado recente a admissão de tramitação de processos judiciais por meio eletrônico. A informatização de processos judiciais passou a ser admitida por força da Lei 
$11.419 / 2006^{44}$ que dispõe em seu artigo inaugural sobre o uso de meio eletrônico na tramitação de processos judiciais, comunicação de atos e transmissão de peças processuais. Tal possibilidade jurídica aplica-se indistintamente aos processos civil, penal e trabalhista, bem como aos juizados especiais, em qualquer grau de jurisdição.

A partir de então, expandiu-se a prática de atos processuais, comunicação e transmissão de peças jurídicas por esse modo, conservando, no entanto, a necessidade de comparecimento presencial das partes e operadores do direito para a concretização de alguns atos processuais específicos, como audiências de conciliação ou instrução, por exemplo.

Com ênfase na possibilidade jurídica de tramitação de processos judiciais eletrônicos na seara dos Juizados Especiais há no ordenamento jurídico importante inovação legislativa com a possibilidade de realização de conciliação não presencial conduzida pelo Juizado mediante o emprego dos recursos tecnológicos disponíveis de transmissão de sons e imagem em tempo real ${ }^{45}$.

A Lei Federal $n^{\circ} 13.994 / 2020$ foi a base legal que incluiu no texto da Lei dos Juizados Especiais Cíveis e Criminais ${ }^{46}$ a possibilidade de realização de conciliação não presencial adotando recursos tecnológicos disponíveis para promover a audiência de tentativa de composição consensual entre as partes.

Do ponto de vista tecnológico não houve qualquer inovação hábil para o processo judicial em si, poisa implementação do processo eletrônico em seus aspectos gerais não foi alterado e não há qualquer modificação nos atos processuais ou forma de transmissão de peças processuais.

Ao contrário, a inovação legislativa que admite a realização de conciliação no âmbito do Juizado Especial Cível vem aumentar o rol de atos processuais já admitidos por via eletrônica tendo em vista que atualmente é possível a realização de depoimento pessoal, oitiva de testemunhas, acareação e até mesmo sustentação oral utilizando-se recursos tecnológicos como videoconferência ou outros meios digitais que garantam a transmissão de áudio e imagem em tempo real, positivados por força da lei processual civil vigente.

Ademais, a possibilidade jurídica de conciliação não presencial conduzida no Juizado

\footnotetext{
${ }^{44}$ BRASIL. Lei Federal no 11.419, de 19 de dezembro de 2006 - "Informatização de Processo Judicial”. Disponível em: http://www.planalto.gov.br/ccivil_03/_ato2004-2006/2006/lei/111419.htm. Acesso em: 26.06.2020

${ }^{45}$ BRASIL. Lei Federal no 13.994, de 24 de abril de 2020 - "Conciliação não Presencial no Âmbito dos Juizados Especiais Cíveis”. Disponível em: http://www.planalto.gov.br/ccivil_03/_ato2019-2022/2020/lei/113994.htm. Acesso em: 20.06.2020.

${ }^{46}$ BRASIL. Lei Federal no 9.099, de 26 de setembro de 1995 - “Juizados Especiais Cíveis e Criminais”. Disponível em: http://www.planalto.gov.br/ccivil_03/leis/19099.htm. Acesso em: 21.06.2020.
} 
Especial vai exatamente ao encontro dos princípios norteadores do processo em trâmite sob a égide da Lei Federal no 9.099/95 que regula o Juizado Especial Cível, pois, como se verifica no Artigo $2^{\circ}$ da Lei supracitada o processo orientar-se-á pelos critérios da oralidade, simplicidade, informalidade, economia processual e celeridade, com vistas, sempre que possível na conciliação e transação como forma de resolução de conflito, revelando-se a conciliação não presencial adequada e coerente aos princípios e objetivos da Lei 9.099/95.

\subsection{AS INOVAÇÕES TECNOLÓGICAS COMO INSTRUMENTOS GARANTIDORES DO ACESSO À “ORDEM JURÍDICA JUSTA” POR MEIO DA CONCILIAÇÃO}

Dentre todas as peculiaridades que reveste o ordenamento jurídico, uma se revela especialmente complexa diante do cenário atual que vivemos: fazer com que o Direito seja atual diante das transformações sociais.

A dificuldade de manter uma atuação jurídica pautada nos mais avançados métodos reside justamente na velocidade em que as informações são produzidas e transmitidas com base nas novas tecnologias.

Tal complexidade se encontra difundida entre todos os atores principais da atividade jurídica, desde o legislador que deve acompanhar os rápidos e dinâmicos movimentos da sociedade e legislar de acordo com as demandas e anseios sociais, dos pesquisadores em aprofundar-se em questões jurídicas contemporâneas, dos juristas que contribuem para a boa administração da justiça e têm a responsabilidade profissional de manter sua atuação dentro da ordem legal e o Poder Jurisdicional do Estado que detém a centralização dos julgamentos e decisão dos litígios.

As robustas e tradicionais bases do Direito são constantemente desafiadas a contemplar situações decorrentes de novas realidades e relações jurídicas às quais a legislação, dado ao seu processo de formação rígido, por vezes tem dificuldade de regular.

Exemplo claro disto é a rápida resposta dos empreendedores digitais inseridos em startups voltadas à seara jurídica como legaltechs e as lawtechs em desenvolverem plataformas voltadas à solução de conflitos online, facilitando a composição entre as partes de forma não presencial.

Apesar da morosa tramitação legislativa e a dificuldade do processo legislativo em acompanhar as mutações dinâmicas das relações sociais é inegável que a Lei Federal $n^{\circ}$ 13.994/2020 deu um importante passo processual-tecnológico dado ao possibilitar a realização 
de conciliação não presencial aos processos judiciais, ampliando as possibilidades de resolução de conflitos a partir de meios consensuais, transpondo barreiras territoriais e ainda contemplando uma das vertentes do consagrado verbete constitucional que garante o acesso a justiça.

No entanto, apesar dos avanços do ponto de vista legal, não há como desconsiderar a má redação legislativa que, em determinadas ocasiões, impõe o cerceamento da possibilidade de composição para àqueles que, por algum motivo, não tenham comparecido na tentativa de conciliação não presencial.

Isto porque, o artigo 23 da Lei Federal n 9.099/95, já com redação atualizada, impõe àqueles que não comparecerem ou recusarem participar da conciliação não presencial a remessa dos autos judiciais ao Juiz togado para que profira sentença.

Insta consignar que a realidade econômica de nosso país não é das mais favoráveis e há de se considerar a necessidade de inclusão digital, pois não são todas as pessoas que têm acesso às tecnologias necessárias para participar das conciliações não presenciais. É bem verdade que terão àqueles que se recusarão a participar, mesmo com reais condições tecnológicas, mas, ignorar a carência de recursos tecnológicos por parte significativa da população é uma forma de tolher a possibilidade legal de composição consensual.

É necessário considerar a exclusão digital como uma realidade, porém não se mostra razoável interromper os avanços tecnológicos na prestação da tutela jurisdicional baseado nesta problemática. Para que as inovações tecnológicas no âmbito processual não se tornem em mais um obstáculo à obtenção de informação e garantia de acesso à justiça, cabe aos atores responsáveis assumir suas atribuições. É necessário, para tanto, que o governo, juntamente com os tribunais busque soluções e promoções de políticas públicas de inclusão digital dos jurisdicionados que ainda carecem de tais recursos.

A utilização de ferramentas tecnológicas no âmbito do processo judicial tem o objetivo de buscar maior alcance e efetividade da prestação jurisdicional e o avanço tecnológico na seara jurídica deve estar alinhada aos preceitos constitucionais de servirem como instrumentos garantidores do acesso à ordem jurídica justa, especialmente quando viabiliza a possibilidade de conciliação, mesmo que não presencial.

$\mathrm{O}$ acesso à justiça não deve ser pensado limitadamente com a garantia de o cidadão ingressar com a ação judicial, independentemente de sua situação econômica, mais além, contempla ainda a duração razoável do processo e resposta justa aos conflitos apresentados por meio do aprimoramento da prestação jurisdicional e proporcionar meios alternativos de solução 
de conflitos.

É exatamente nesse sentido que as novas tecnologias vêm no auxílio do acesso à justiça, à medida que simplifica procedimentos, facilita o acompanhamento processual por parte dos jurisdicionados, adéquam os critérios balizadores da razoável duração do processo e ainda admite a prática processual não presencial.

\section{CONCLUSÃO}

Pode-se considerar que, dentre os desafios enfrentados pelo sistema jurídico brasileiro contemporâneo, as máculas referentes às garantias ao acesso à justiça, ou à ordem jurídica justa, são de relevante destaque, pois demonstram que, os óbices identificados no chamado Projeto Florença, por Mauro Cappelletti, atualmente permanecem mitigando a efetividade da justiça brasileira.

É de se destacar, entretanto, que os obstáculos de natureza financeira, temporal, psicológica e cultural, e institucional podem, e em regra são, ser neutralizados por meio dos métodos de resolução consensual de conflitos, seja na esfera judicial ou extrajudicial, por meio da negociação, conciliação, mediação ou arbitragem.

Nesse sentido, de se entender o ensejo ao fomento e regulamentação da matéria, o que, no Brasil, ganha enfoque com a Resolução $n^{\circ}$ 125/2010 do CNJ e das próprias disposições do Novo Código de Processo Civil de 2015.

Entretanto, constata-se que a mera observância aos institutos pode, por vezes, não se mostrar plenamente suficiente à garantia do acesso à ordem jurídica justa, principalmente em função de, por vezes, verificar-se dificuldade na implementação dos métodos de resolução pacífica dos litígios em virtude de fatores diversos como, por exemplo, a necessidade de distanciamento social, como visto no ocorrido no ano de 2020 com a pandemia do COVID-19.

Ocorre que, não se pode olvidar que, atualmente, percebe-se a chamada sociedade digital, pelo que as inovações tecnológicas intrínsecas no cotidiano nas mais diversas áreas da ciência não só podem, mas devem ser utilizadas pelos operadores do Direito como forma de responder aos anseios desta seara, haja vista que, como constatado por inúmeras vezes, àquelas possuem, por seus próprios métodos, a possibilidade de identificar, sistematizar e apresentar propostas para solução dos problemas (dores) enfrentadas pela prática jurídica.

São os exemplos as organizações exponenciais, cuja potencialidade, seja disruptiva ou incrementadora, otimizam a aplicação do direito e colaboram para neutralização de riscos ou 
na melhoria no enfrentamento de temas que, no âmbito estritamente jurídico, ver-se-iam limitados ou estagnados.

Destacam-se, assim, as startups jurídicas, ou também chamadas de lawtechs ou legaltechs, as quais buscam a facilitação na solução de problemas jurídicos enfrentados cotidianamente pelos indivíduos que, de alguma forma, necessitarão das soluções jurídicas ou pelos operadores do direito.

A vantagem é que, por utilizarem das inovações tecnológicas, possuem condições de, a partir da interdisciplinaridade, criar mecanismos diferenciados à tratativa dos problemas submetidos à análise.

Veja que, no caso da resolução consensual de conflitos, as plataformas digitais são exemplos de mecanismos utilizados por inúmeras startups jurídicas para implementar a mediação, conciliação e a negociação, o que, consequentemente, colabora à soluçãodas problemáticas concernentes ao acesso à ordem jurídica justa.

Por isso se mostra de suma importância o enfoque aos chamados ecossistemas de inovação, pois, desta forma, restará garantido o investimento pelos inúmeros organismos sociais como instituições de ensino, setor privado e o Estado, no desenvolvimento de ações, pesquisas e estudos voltados ao desenvolvimento de instrumentos para garantia de evolução das formas e métodos postos à mitigação dos óbices enfrentados.

Ocorre que, por vezes, o que se constata é a inobservância à ciência ou aos investimentos nos métodos utilizados por esta, o que, in casu, resulta na mácula à formação dos referidos ecossistemas, a exemplo do próprio Estado que, embora restando evidente a possibilidade de otimização da garantia à justiça plena por meio das inovações tecnológicas, somente no ano de 2020, com a promulgação da Lei Federal nº 13.994/2020, motivado pela necessidade advinda do distanciamento social causado pela pandemia do COVID-19, buscou formas de garantir a continuidade das audiências de conciliação e mediação no âmbito judicial pelo meio digital, o que muito tempo já era visto e estudado no âmbito privado.

Assim, tem-se que, muito mais do que meros estudos técnicos e reservados à academia, quando no âmbito da transformação digital nas temáticas jurídicas, ambas as áreas possuem grande perspectiva de crescimento, pois há vasto campo a ser explorado e investido, o que, invariavelmente, colaborará com o aprimoramento e melhoria da justiça.

\section{REFERÊNCIAS}


ALVES, Cleber Francisco. A estruturação dos serviços de assistência jurídica nos Estados Unidos, na França e no Brasil e sua contribuição para garantir a igualdade de todos no Acesso à Justiça. 614f. Tese (Doutorado em Direito). Faculdade de Direito, PUC/RJ, Rio de Janeiro, 2005.

AUDY, Jorge; PIQUÉ, Josep. Dos parques científicos e tecnológicos aos ecossistemas de inovação: Desenvolvimento social e econômico na sociedade do conhecimento. Brasília, DF: ANPROTEC, 2016.

BLANK, Steve; DORF, Bob. Startup: manual do empreendedor. Alta Books Editora, 2014.

BRASIL. Lei Federal $\mathrm{n}^{\mathrm{o}}$ 11.419, de 19 de dezembro de 2006 - Informatização de Processo Judicial. Disponível em: http://www.planalto.gov.br/ccivil_03/_ato20042006/2006/lei/111419.htm. Acesso em: 26.06.2020.

Lei Federal no 13.105, de 16 de março de 2015 - Código de Processo Civil Brasileiro. Disponível em: http://www.planalto.gov.br/ccivil_03/_ato2015-2018/2015/lei/113105.htm. Acesso em: 12.06.2020.

Lei Federal no 13.243, de 11 de janeiro de 2016 - Marco Legal de Ciência, Tecnologia $e \quad$ Inovação. Disponível em: http://www.planalto.gov.br/ccivil_03/_ato20152018/2016/lei/113243.htm. Acesso em: 12.06.2020.

. Lei Federal no 13.994, de 24 de abril de 2020 - Conciliação não Presencial no Âmbito dos Juizados Especiais Cíveis. Disponível em: http://www.planalto.gov.br/ccivil_03/_ato20192022/2020/lei/113994.htm. Acesso em: 20.06.2020.

Lei Federal no 9.099, de 26 de setembro de 1995 - Juizados Especiais Cíveis e Criminais. Disponível em: http://www.planalto.gov.br/ccivil_03/leis/19099.htm. Acesso em: 21.06.2020.

CAPPELlETTI, Mauro; GARTH, Bryant. Acesso à justiça. Trad. e Rev. Ellen Gracie Northfleet. Porto Alegre, 1982.

CONSELHO NACIONAL DE JUSTIÇA. Justiça em Números 2019. Conselho Nacional de Justiça. Disponível em: https://www.cnj.jus.br/pesquisas-judiciarias/justica-em-numeros/. Acesso em: 29.06.2020.

CONSELHO NACIONAL DE JUSTIÇA. Resolução $n^{\circ}$ 125, de 29 de novembro de 2010. Disponível em: https://atos.cnj.jus.br/atos/detalhar/atos-normativos?documento=156. Acesso em 12.06.2020.

DRUCKER, Peter Ferdinand. Inovação e espírito empreendedor: práticas e princípios. São Paulo: Pioneira, 1986.

FEIGELSON, Bruno. Sandbox: primeiras reflexões a respeito do instituto. Revista de Direito e as Novas Tecnologias. São Paulo, v.1, out-dez 2018. 
FOLZ, Christian. Ecossistema Inovação. Fábio Carvalho editores técnicos. Brasília, DF : Embrapa, 2014

FREEMAN, Chris. The economics of industrial innovation. 2. ed. London: Frances Pinter, 1982.

GRECO, Silvana. Los aportes de la mediación y de los procesos colaborativos de gestión de conflictos para la transformación de la cultura del litigio. Revista de Ciencias Jurídicas y Sociales, n. 4, 2006.

CARVALHO, Angela Maria Grossi de; SANTOS, Plácida Leopoldina Ventura Amorim da Costa. Sociedade da informação e a aplicação da informação na sociedade contemporânea. In: DT5 do IX Encontro dos Grupos/Núcleos de Pesquisas em Comunicação, XXXII Congresso Brasileiro de Ciências da Comunicação. Curitiba, 2009. Disponível em: http://www.intercom.org.br/papers/nacionais/2009/resumos/R4-2483-1.pdf

JOAQUIM, Bruna; MENDES, Fernando Lúcio; ESTEVES, Paulo Cesar Leite. Ecossistemas de inovação: uma análise exploratória da literatura. In: Anais do VIII Congresso Internacional de Conocimiento e Innovación (ciki). v. 1, n. 1, 2018. Disponível em: https://proceeding.ciki.ufsc.br/index.php/ciki/article/view/502.

KON, Anita. Ecossistemas de inovação: a natureza da inovação em serviços. Revista de Administração, Contabilidade, e Economia da Fundace, 2016.

MARINONI, Luis Guilherme. Novas linhas do processo civil: o acesso à justiça e os institutos fundamentais do direito processual. 2. ed. São Paulo: Revista dos Tribunais, 1997.

MAURI, Gabriela de Nadai; LIMA, Jairo Gustavo de; POZO, Osmar Vicente Chévez; FREITAS, Rodrigo Randow de. Startups no agronegócio brasileiro: uma revisão sobre as potencialidades do setor. Brazilian Journal of Production Engineering-BJPE, v. III, n. 1, p. 107-121, 2017.

MELLO, Kátia Sento Sé; BAPTISTA, Bárbara Gomes Lupetti. Mediação e conciliação no judiciário: dilemas e significados. Dilemas - Revista de Estudos de Conflito e Controle Social, v. 4, n. I, p. 97-122, 2011.

OLIVEIRA, Marcella Beraldo de. Justiças do diálogo: uma análise da mediação extrajudicial. 330f. Tese (Doutorado em Ciências Sociais) - Universidade Estadual de Campinas, Instituto de Filosofia e Ciências Humanas, Campinas/SP, 2010.

PEIXOTO, Fabiano Hartmann. Projeto Victor: relato do desenvolvimento da inteligência artificial na repercussão geral do Supremo Tribunal Federal. Revista Brasileira de Inteligência $\begin{array}{lllll}\text { Artificial } & \text { e } & \text { Direito. } & \text { D.1, } & \text { Disponível }\end{array}$ https://rbiad.com.br/index.php/rbiad/article/view/4.

PLONSKI, Guilherme Ary. Bases para um movimento pela inovação tecnológica no brasil. São Paulo Em Perspectiva, v. 19, n. 1, p. 25-33, jan./mar. 2005. 
RIES, Eric. A startup enxuta: como os empreendedores atuais utilizam a inovação contínua para criar empresas extremamente bem-sucedidas. São Paulo: Lua de Papel, 2012.

SANTOS, Gabriel Sant'Ana Palma. Organizações exponenciais: uma análise do desenvolvimento de startups na incubadora MIDI Tecnológico. 236f. Tese (Doutorado em Engenharia). Universidade Federal de Santa Catarina, Centro Tecnológico, Programa de PósGraduação em Engenharia e Gestão do Conhecimento, Florianópolis/SC, 2018.

SIMÕES, Janaína. Automação no direito: Um novo tipo de startup, as legaltechs, desenvolve sistemas tecnológicos para a área jurídica. Revista Pesquisa FAPESP, 2018. Disponível em: https://revistapesquisa.fapesp.br/2018/09/18/automacao-no-direito/. Acesso em: 27.05.2020.

SOUZA, Luciana Moessa de (org.). Mediação de conflitos: novo paradigma de acesso à justiça. 2 ed. Santa Cruz do Sul: Essere nel Mondo, 2015.

SUPREMO TRIBUNAL FEDERAL. Inteligência artificial vai agilizar a tramitação de processos no STF. Notícias STF. Publicado em quarta-feira, 30 de maio de 2018. Disponível em: http://www.stf.jus.br/portal/cms/verNoticiaDetalhe.asp?idConteudo=380038. Acesso em 12.06.2020.

VASCONCELOS, Carlos Eduardo. Mediação e práticas restaurativas. São Paulo: Método, 2008.

VIEIRA, Tatiana Cubeiros. CASTANHO; Maria Eugênia. Sociedade atual e revolução da informação: ganhos e perdas. Contrapontos. Itajaí, v.8, n.2, p. 171-185, mai-ago 2008.

WATANABE, Kazuo. Acesso à ordem jurídica justa (Conceito atualizado de acesso à justiça) processos coletivos e outros estudos. Del Rey: Belo Horizonte, 1969.

\section{DADOS DA PUBLICAÇÃO}

Categoria: artigo submetido ao double-blind review.

Recebido em: 28/10/2020.

Aceito em: 01/04/2021. 


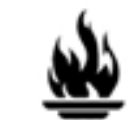

서요 